\section{Outstanding Business Reference Sources 2015}

E ach year, the Business Reference Sources Committee of BRASS selects the outstanding business reference sources published since May of the previous year. This year, the committee reviewed sixteen entries; of these, two were designated as "Outstanding," six as "Notable," and one as a "Notable New Edition." To qualify for the award, the title must meet the conventional definition of reference: a work compiled specifically to supply information on a certain subject or group of subjects in a form that will facilitate its ease of use. The works are examined for the following: authority and reputation of the publisher, author, or editor; accuracy; appropriate bibliography; organization; comprehensiveness; value of the content; currency; distinctive addition; ease of use for the intended purpose; quality and accuracy of index; and quality and usefulness of graphics and illustrations. Additional criteria for electronic reference titles are accuracy of links, search features, stability of content, and graphic design. Works selected must be suitable for medium to large-size academic and public libraries.

\section{OUTSTANDING}

\section{BRASS Business Reference Sources Committee}

BRASS Business Reference Sources Committee contributing members: Naomi Lederer, selections editor; Ed Hahn, chair; Erin Wachowicz, nominations coordinator; Felipe Castillo; Holly Inglis; Jordan Nielsen; Anthony Raymond; Lauren Reiter; and Suzanne Sweeney.

For information contact Naomi Lederer, Professor, College Liaison and Government Information Librarian, Colorado State University, Fort Collins, CO 80523-1019; email:naomi.lederer@colostate.edu.
The Routledge Companion to Entrepreneurship. Edited by Ted Baker and Friederike Walter. New York: Routledge, 2015. 500 p. \$240 hardcover (ISBN: 978-0-415-63176-1).

This insightful collection of works, edited by Ted Baker (North Carolina State University) and Friederike Walter (University of Siegen, Germany), explores the diverse ideas, perspectives, theories, and methods in the field of entrepreneurship scholarship. There exists a strong interest in entrepreneurship, from both scholars and practitioners, and research has moved from being an outlier to mainstream. This volume provides wide-ranging look at the issues surrounding entrepreneurship, such as exploring the definition of the term entrepreneurship in the creative industries and developing countries. Baker and Walter are enthusiastic about the current scholarship in this area, stating in their opening chapter: "the domain of entrepreneurship is broader, more contested, more energetic and more promising than it ever has been."

Organizationally, the book is divided into six broad themes and includes a brief introduction to each section. Readers will find additional recommended readings and references at the end of each chapter. The first section, "The Discipline of Entrepreneurship," explores the history of the field, the philosophy of entrepreneurship, and what the term 
entrepreneurship means to different groups. "Reasons and Motivations for Entering Entrepreneurship" examines why people engage in entrepreneurship-investigating passion, differences between entrepreneurs and other people, and those who start business after business. Next, "Resources and Resourcefulness" contains chapters on the creativity entrepreneurs demonstrate in using available resources, microfinancing, and the commercialization of inventions and discoveries at universities. Included is an interesting investigation into how families and households influence business decisions.

The book continues with the positive and negative impacts of entrepreneurship on entrepreneurs and their families, communities, and broader society in "Entrepreneurship, Wealth, and Wellbeing." In this section there is a fascinating look at the area of criminal entrepreneurship. One of the strengths of this book is the inclusion of future research questions and, within this chapter, the author suggests that researchers develop a better understanding of whether criminal entrepreneurship is "merely a sub-discipline at the nexus between entrepreneurship and criminology." Next, in "Entrepreneurial Opportunity," researchers discuss the differences in opportunities facing various groups, such as women in the global south. Finally, "Towards a Broader Understanding" looks at the methodological future of entrepreneurship research. There are chapters outlining the steps for conducting a content analysis, potential areas for research in developing countries, techniques for getting inside entrepreneurs' hearts and minds, and a critical examination of research scholarship in the field of entrepreneurship.

This book is an outstanding resource for scholars by offering to readers an understanding of a wide array of issues related to entrepreneurship scholarship. In addition, it is strengthened by bringing together scholars and their research traditions from many different countries, primarily in the United States, Canada, and Europe. These contributors bring a breadth of experiences and diverse backgrounds. This work is an excellent addition to academic libraries serving graduate students and faculty engaged in entrepreneurship scholarship and will provide new insights and directions for future research.-Felipe Castillo, Seattle University, Seattle, Washington

The Sage Encyclopedia of Quality and the Service Economy. Edited by Su Mi Dahlgaard-Park. Thousand Oaks, CA: Sage Publications, 2015. 2 vols. 958 p. $\$ 375$ hardcover (ISBN: 978-1-4522-5672-6). \$300 e-book (978-1-5063-1505-8).

This two-volume reference resource begins its introduction by stating that our global society has entered into what is now a service economy and that service now makes up the largest share of the GDP in many countries. The Sage Encyclopedia of Quality and the Service Economy identifies that the emphasis on quality gained importance with mass production in the 1930s, and during the Second World War in the 1940s where large amounts of military supplies could be produced in a short period and at a reasonable cost. Since the 1990s up through the present day, the emphasis on quality has expanded to include service sectors.

The editor of this publication, Dr. Su Mi Dahlgaard-Park, has compiled more than two hundred articles written by more than two hundred contributors, many of whom are affiliated with universities worldwide. All of the articles give a succinct overview of a range of topics and include a section where the reader can get further information. Topics include the areas of advertising, entrepreneurship, innovation management, knowledge management, leadership, and quality assurance. For example, the article on leadership includes a definition of leadership and an overview of the various leadership theories such as trait and situational theories. Also included is an overview of the theory of elemental change management where the focus is not on individual leaders, but the many roles one or more leaders may face in an organization. These include the roles of the strategist, controller, storyteller, and resource allocator. In another example, the article on knowledge management starts with a definition, then focuses in the areas of knowledge types within an organization, knowledge management and learning organizations, knowledge management and technology, and knowledge management for quality.

In addition to being the editor of this resource, Dahlgaard-Park is currently a professor at Lund University's Institute of Service Management in Sweden. She is recognized as a leading scholar in the areas of quality and services management, knowledge management, and human resource management.

All of the articles in this resource are arranged alphabetically, and each volume has its own A-Z table of contents along with a list of entries. In addition to the table of contents, each volume has a readers' guide where all of the articles are classified into twenty related topics. Some of these topics include branding, communication and social media, consumption, and tourism. The end of the second volume includes an extensive bibliography and a detailed index.

As service continues to become more integrated in the everyday economy and the need for quality never ends, The Sage Encyclopedia of Quality and the Service Economy can serve as an outstanding reference resource in academic libraries, for students and faculty in the areas of leadership, knowledge management, marketing, and diversity.-Ed Hahn, Weber State University, Ogden, Utah

\section{NOTABLE}

Creating Value with Big Data Analytics: Making Smarter Marketing Decisions. By Peter C. Verhoef, Edwin Kooge, and Natasha Walk. London and New York: Routledge, 2016. 316 p. \$59.95 paperback (ISBN: 978-1-138-83797-3). \$150 hardback (9781-138-83795-9).

In recent years, big data analytics has become a big deal in business. What makes this a notable selection is the specific focus of this book. It isn't just about big data, it's about 


\section{FROM COMMITTEES OF RUSA}

using big data to create value and make better marketing decisions.

To accomplish this, the authors, an academic and two data analysts, present a model for creating value with data analytics and use this as a framework for the book. It is comprised of three types of chapters: general, key, and in-depth. The general chapters present an overview and history of data analytics and a detailed explanation of their big data value creation framework. The key chapters discuss big data analytics in the context of business and marketing. This includes chapters on data types, how big data are changing analytics, and building successful big data capabilities. The in-depth chapters take a deeper dive into the ideas discussed in the general and key chapters, describing tools and techniques that can be used in real-world settings. The remaining chapters feature cases that demonstrate how big data can be used to solve problems and key learning points that summarize the takeaways of each chapter.

While it is not a traditional reference source, this is a notable book that connects big data analytics concepts with practical applications for marketing. A table of contents, an index, and a guide that helps readers navigate the sections of the book make it easy to find specific content. The combination of introductory stand-alone chapters and in-depth, advanced chapters make this suitable for use as a reference title. It is recommended for advanced students and business and data professionals that are interested in market research and data analytics._Erin Wachowicz, Yale University, New Haven, Connecticut

Palgrave Dictionary of Emerging Markets and Transition Economics. Edited by Jens Hölscher and Horst Tomann. London: Palgrave MacMillan, 2015. 589 p. $\$ 239$ hardcover (ISBN: 978-1-137-37137-9), \$189 e-book (978-1-137-37138-6).

The Palgrave Dictionary of Emerging Markets and Transition Economics has been selected as a notable title for its contributions from primarily European economists, sociologists, finance, and political science experts. As stated by the editors in the introduction, the format follows the example of The New Palgrave Dictionary of Economics, which uses an encyclopedia-based approach where articles not only define the terms but provide an overview of the evolution of the term or theory, and also touch on the current debates. The articles will be particularly useful to researchers interested in select European and Asian countries. There is some global analysis or perspective included; however, it is best to look elsewhere for research specific to other regions. Historical coverage varies by topic; typically 1980s-1990s to present as it examines transition from communism to capitalism.

The dictionary is divided into five parts: "Monetary Aspects," "Institution Building," "Economic Policy," "Growth and Development," and "Wellbeing." Each part has five to seven articles, which include abstracts and reference lists. There is both a name and subject index.

A strength of this monograph is the balance between economic, political and sociological studies. Part 1, "Monetary
Aspects," includes stellar analysis of central bank independence, currency reform, financial sector restructuring, exchange rate regime, and monetary stabilization. The articles on entrepreneurship and corporate social responsibility in part 4, "Growth and Development," have excellent definitions, historical analysis and current perspective for any researcher looking for a source to begin with for those topics. For researchers looking at entrepreneurship from an academic focus, the variety of entrepreneurship definitions included will be valuable as well as the thoughtful analysis of entrepreneurs in transition economies. Due to its useful definitions, the Palgrave Dictionary of Emerging Markets and Transition Economics is highly recommended for academic libraries looking to provide their undergraduate students with a solid introduction to transition economics and emerging markets.- - Holly Inglis, University of Toronto, Toronto, Ontario

The 100 Most Important American Financial Crises: An Encyclopedia of the Lowest Points in American Economic History. By Quentin R. Skrabec Jr. Santa Barbara, CA: ABC-CLIO, Greenwood, 2015. 337 p. \$89 hardcover (ISBN: 978-1-44083011-2). Contact the publisher for e-book price.

This encyclopedia is notable as a chronicle of the worst moments in American financial and economic history. The 100 Most Important American Financial Crises: An Encyclopedia of the Lowest Points in American Economic History begins with Bacon's Rebellion in 1676 and ends with Detroit's Bankruptcy in 2013, covering a wide variety of economic events that range from the well-known to the less-obvious. A small sampling of entries includes "Whiskey Tax Rebellion," "Gold Rush Boom and Bust," "Bessemer Process and the Labor Crisis," "Peanut Import Crisis," "Wall Street Crash and Great Depression," and "Hurricane Katrina."

All of entries were written as two-to-three-page narratives, occasionally supplemented with images. The storytelling style is clear, accessible, and successful in conveying the details and magnitude of each individual crisis. Additionally, the well-researched entries use cross-referencing to relate each economic problem to other important crises and include a few suggestions for further reading. This encyclopedia is available in print and electronic formats, each containing a lengthy appendix of primary documents, as well as a bibliography and index.

The 100 Most Important American Financial Crises: An Encyclopedia of the Lowest Points in American Economic History covers a topic of current interest as readers and researchers reflect on recent financial crises and seek historical information for context and comparison. The encyclopedia is suitable for both public and academic libraries, and is a timely, useful, and engaging resource that will inform users interested in surveying the impact of historical financial and economic disasters and learning more about events that have affected the United States throughout history to the modern day.-Lauren Reiter, Penn State University, University Park, Pennsylvania 
The Minimum Wage: A Reference Handbook. Edited by Oren M. Levin-Waldman. Santa Barbara, CA: ABC-CLIO, 2016. 354 p. \$58 hardcover (ISBN: 978-1-4408-3394-6), \$58 (1 user) e-book (978-1-4408-3395-3).

Debate among economists over the theoretical and actual efficacy of a minimum wage seems as intense today as it ever was and in the American political arena the debate continues to be contentious and sharply divided along party lines. While not a completely balanced treatment, this recent addition to ABC-CLIO's Contemporary World Issues series is notable because it provides essential background on the struggle for, and against, a minimum wage law that is accessible to those who have little or no knowledge of the history behind it. It provides an introduction to the wide ranging socioeconomic and political motivations and controversies that have surrounded the minimum wage in the United States since it was first enacted into law in 1938 in the Fair Labor Standards Act.

That this book gives greater space to arguments prominimum wage is understandable given Levin-Waldman's decades-long advocacy for and defense of a minimum wage. Nor is it surprising that all issues affecting minimum wage policy cannot be addressed in this one volume. The almost sixty pages of data and excerpts from primary documents prove very useful. The table of demographics provides data not easily or quickly retrievable by the inexperienced researcher. The resources for further research is a thirty-five page annotated bibliography of books, articles, reports and Internet resources. The chronology gives a succinct overview from the world's first adoption of a minimum wage by New Zealand in 1894 to the recent raise of the minimum wage to $\$ 15$ an hour in Portland, Oregon in 2015. The glossary explains many of the esoteric terms used throughout the book. One caveat is the index is too brief and not particularly useful. For example, there is no index entry for the word political, but a full-text search for political debate in the ebook brings up five entries. Public and academic libraries wanting to support research on this hot button topic should have this book.-Anthony Raymond, Santa Clara University, Santa Clara, California

The Sage Encyclopedia of Economics and Society, Frederick F. Wherry, general editor; Juliet Schor, consulting editor. Los Angeles: Sage, 2015. 1853 p. \$650 hardcover (ISBN: 9781-4522-2643-9). \$520 e-book (ISBN: 978-1-5063-0088-7).

The Sage Encyclopedia of Economics and Society is notable for its coverage of economics highlighting contemporary issues and society, demonstrating how economics and social issues are intertwined. This four-volume 1,853 pages (plus front mater) set covers a wide range of economic topics including 800 articles, each around 3 to 5 pages. Topics range from ABC (TV) to Customer Satisfaction, Daoism to Italian Immigration, Japanese Immigration to Rural Migrants, and Sacred Production to YouTube. There are articles as diverse as Stalking and Twitter; Peter Drucker and Black Baptist Women's Movement; Quality Circles and Kickstarter. Each article is signed and includes references and future readings. There are cross-references between articles and each volume includes a list of all articles and a reader's guide arranging all articles into fifteen broad categories including "Advertising and Marketing," "Childhood and Economics," "Education and Human Capital," "Religious Life," and "Work and Occupations." The first volume also includes about the editor, list of contributors, introduction, and chronology of economics and society. There are some international contributors, but the focus is on US society and economics. The last volume also includes a glossary; resource guide to sources of US data; international data; books, journals, and websites; and an index. The general editor is an economic and cultural sociologist from Yale University and the Consulting Editor is a professor of sociology at Boston College.

This academic, multi-author reference work provides a general, non-technical resource that is understandable and tangible. It provides better understanding of economics through a contemporary and social viewpoint. It is available both in print and electronic versions are on various platforms including Sage Knowledge, Amazon Kindle, and Google Play.-Suzanne Sweeney, Collin College, McKinney, Texas

Worldmark Global Business and Economy Issues. Farmington Hills, MI: Gale, 2015. 2 vols. 706 p. \$326 hardback (ISBN: 978-1-4103-1756-8). Contact the publisher for e-book price (ISBN: 978-1-4103-1759-9).

The publisher's website explains that this notable reference book is "intended to meet the needs of global studies courses as well as International Baccalaureate and AP courses in Economics and Business \& Management, [it] is designed to give students and researchers a resource that helps contextualize and analyze the central issues surrounding international business and economics." Arranged by topic, with a glossary of terms (abnormal profits to WTO); chronology of events (prehistory and ancient times to January 25, 2015); a bibliography divided by books, periodicals, and websites, as are end-of-entry bibliographies; an index with "see" references, and a selected list of organizations and advocacy groups. The online version's list of illustrations has a thumbnail-sized partial view of the image that links to the full image in the entry from which it came. An unusual section on using primary sources, but part of the reason this book is particularly valuable, provides explanations and context for the documents that are transcribed from other sources, included to pique the interest of researchers.

Volume 1 thematically covers business and management topics: core concepts, business organization and environment, human resource management, finance and accounting, marketing, and operations management. Volume 2's themes are economic topics: foundations, microeconomics, macroeconomics, international economics, and development economics. All the topics are intended to address global impact. All entries have an introduction, historical background, impacts and issues, and future implications sections. For example, the entry on culture starts with an introduction, 


\section{FROM COMMITTEES OF RUSA}

and then covers the historical background (understandings of culture, including business culture), impacts and issues ("glocalization"), and future implications. Launching a PDF version in the e-book creates a sharp-looking color document, with linkable webpages in the bibliography. Because of its clear focus, Worldmark Global Business and Economy Issues permits a speedy location of relevant definitions and related materials. It is going to be a useful resource for a long time.-Naomi Lederer, Colorado State University, Fort Collins, Colorado

\section{NOTABLE NEW EDITION}

The Oxford Handbook of Banking, 2nd ed. Edited by Allen N. Berger, Philip Molyneux, and John O. S. Wilson. Oxford University Press, 2015. 1040 p. \$175 hardcover (ISBN: 9780-19-968850-0).

The first edition of The Oxford Handbook of Banking was published in 2010 during the global financial crisis. Since then, much has changed in the world of banking. Accordingly, the second edition of the Handbook book kicks off with a chapter focused on the financial crisis and its impact on policies and regulations, the banking industry, and banking research. The more than forty experts who contributed to this book include bankers, professors, economists, and policy advisers from all over the world. For these reasons, the second edition of The Oxford Handbook of Banking deserves recognition as a notable new edition.

In terms of organization, the Handbook's table of contents lists five distinct sections, including the theory of banking, operations, regulations and policy, macroeconomic perspectives, and banking systems around the world. A series of lists follows the table of contents that readers will find useful. The first is a list of figures, including figures such as an overview of the financial system, bank acquisitions by year, and bank ownership structure across regions. A list of tables follows, and it includes tables such as major events in bank deregulation, the world's one hundred biggest banks, and banking sector stability and performance indicators. Following the list of tables is a list of abbreviations, ranging from ABCP (asset-backed commercial paper) to PD (probability of default) to VLTRO (very long-term refinancing operations). This book also includes an index to help readers navigate its more than one thousand pages.

While the new edition includes much of the information from the previous edition, it is significantly enhanced by the inclusion of post-financial crisis updates. This book also strikes a nice balance between theory and empirical research, thus making it accessible to researchers and practitioners alike.-Jordan Nielsen, San Diego State University, San Diego, California 